University of Wollongong

Research Online

Faculty of Social Sciences - Papers (Archive) Faculty of Arts, Social Sciences \& Humanities

$1-1-2016$

Implications of proxy efficacy for studies of team leadership in organizational settings

Seyyed B. Alavi

Sharif University of Technology, sbalavi@sharif.edu

John McCormick

University of Wollongong, johnmcc@uow.edu.au

Follow this and additional works at: https://ro.uow.edu.au/sspapers

Part of the Education Commons, and the Social and Behavioral Sciences Commons

Research Online is the open access institutional repository for the University of Wollongong. For further information contact the UOW Library: research-pubs@uow.edu.au 


\title{
Implications of proxy efficacy for studies of team leadership in organizational settings
}

\begin{abstract}
Although there have been numerous studies of self-efficacy and collective efficacy in different contexts, little attention has been paid to proxy efficacy. In this article we propose that a person's self-efficacy may be related to proxy efficacy when achievement of personal goals is related to the performance of the proxy on the person's behalf. We argue this is important in team leadership. We further propose that the extent to which team members believe their leaders efficacious as their proxies may affect team processes and effectiveness. A team level construct, namely team proxy efficacy for the leader, referring to a shared proxy efficacy belief for the team leader, is also proposed. Several propositions involving the role of team proxy efficacy in team processes, and how proxy efficacy may play roles in the emergence and success of shared leadership in teams are developed.
\end{abstract}

\section{Keywords}

proxy, leadership, organizational, settings, efficacy, studies, implications, team

\section{Disciplines}

Education | Social and Behavioral Sciences

\section{Publication Details}

Alavi, S. Babak. \& McCormick, J. (2016). Implications of proxy efficacy for studies of team leadership in organizational settings. European Psychologist, 21 (3), 218-228. 


\title{
Implications of Proxy Efficacy for Studies of Team Leadership in Organizational Settings
}

\author{
Seyyed Babak Alavi ${ }^{1}$ and John McCormick ${ }^{2}$ \\ ${ }^{1}$ Graduate School of Management and Economics, Sharif University of Technology, Tehran, Iran \\ ${ }^{2}$ School of Education, University of Wollongong, NSW, Australia
}

\begin{abstract}
Although there have been numerous studies of self-efficacy and collective efficacy in different contexts, little attention has been paid to proxy efficacy. In this article we propose that a person's self-efficacy may be related to proxy efficacy when achievement of personal goals is related to the performance of the proxy on the person's behalf. We argue this is important in team leadership. We further propose that the extent to which team members believe their leaders efficacious as their proxies may affect team processes and effectiveness. A team level construct, namely team proxy efficacy for the leader, referring to a shared proxy efficacy belief for the team leader, is also proposed. Several propositions involving the role of team proxy efficacy in team processes, and how proxy efficacy may play roles in the emergence and success of shared leadership in teams are developed.
\end{abstract}

Keywords: team leadership, proxy efficacy, self-efficacy, shared leadership

Social Cognitive Theory (SCT) (Bandura, 1986, 1997, 2000, 2001) proposes three types of agency: personal, proxy, and collective. According to Bandura (1997, p. 3), "Agency refers to acts done intentionally." In many situations, individuals may be expected to act intentionally by themselves in order to achieve their goals. However, individuals may sometimes prefer or be required to rely on others as proxy agents to perform given tasks or actions on their behalf. In everyday life, perhaps the most common conceptualization of a proxy relates to circumstances in which people may have little choice but to have a proxy to act on their behalf. For example, persons lacking sufficient knowledge of law may need a lawyer to act on their behalf. We emphasize that a proxy is not merely a means to an end, for example, a newspaper deliverer who provides access to a newspaper. Rather, a proxy is an indirect way of exerting agency.

Bandura (2001) suggested that turning from personal control to proxy control could be a way to be free of burdensome responsibilities and reduce stress, which personal control may entail, and that power and competence may explain why people engage proxy agents. According to Bandura (1997, 2001), outcomes are consequences of agentive acts, and intentions center on plans of actions. Efficacy beliefs are central to any effective action (Bandura, 1986, 1997, 2000, 2001). Self-efficacy refers to “... beliefs in one's capabilities to organize and execute the courses of action required to produce given attainments" (Bandura, 1997, p. 3). Collective efficacy has been defined as "...a group's shared belief in its conjoint capabilities to organize and execute the courses of action required to produce given levels of attainments" (Bandura, 1997, p. 477). Consistent with SCT, we define proxy efficacy as a person or group's (shared) belief that another person or group has capabilities to organize and execute courses of action on her, his, or its behalf, to produce given levels of attainment. In some contexts, proxy efficacy may be similar to perceived ability of another, however, there are critical differences. One may perceive other individuals or teams to be capable performers of their roles, but not perceive them as proxies capable of assisting them to achieve goals. We emphasize that a necessary condition for the existence of proxy efficacy is that a person or collective must be perceived to act as a proxy.

Although proxy efficacy may readily explain different social phenomena in different contexts, such as relationships between lawyers and clients, physicians and patients, coaches and sport players, and teachers and parents, we argue that this construct has particular salience for organizational settings. Individuals' proxy efficacy beliefs for key colleagues such as their leaders, senior managers, coworkers, and teammates, or board members' proxy 
efficacy for their CEO, may play a key role in motivational processes and affect some organizational behaviors. In organizations, individuals might not have all the means to successfully complete activities. Indeed, there may be a variety of reasons for having a proxy in an organizational setting. For example, people may think that others can perform certain activities better than them in some situations, for example, gaining organizational resources.

Organizations are typically structured to limit the activities of individuals by defining roles. For example, upper management is likely to deal with a team through the conduit of a team leader, rather than with individual team members (Druskat \& Wheeler, 2004). Consequently, there are likely to be times when the team leader acts as a proxy of upper management. A team leader can also be considered a proxy for the team, for example, when the team leader is solely responsible for collecting organizational resources for the team by negotiating with top managers or coordinating team activities with other teams.

In the context of team leadership, proxy efficacy for a team leader may be operationalized in terms of leadership functions suggested by some researchers (e.g., Fleishman et al., 1992; Zaccaro, Rittman, \& Marks, 2001) if team members expect their team leader to act on their behalf to assist the team in those functions. For example, team members may develop different levels of proxy efficacy for their team leader in terms of using information in problem solving, managing personnel resources (Fleishman et al., 1992), or acquiring necessary resources for the team (Zaccaro, Heinen, \& Shuffler, 2009).

Despite extensive studies of self-efficacy and collective efficacy in many different contexts (e.g., Baker, 2001; Bandura, 1986, 1993, 1997, 2000, 2001; Collins \& Parker, 2002; Kellett, Humphrey, \& Sleeth, 2000; Pajares, 1996; Watson, Chemers, \& Preiser, 2001; Wood \& Bandura, 1989; Zaccaro et al., 2001), it seems proxy efficacy has not been studied in the context of organizational processes despite its arguable importance.

We searched the Social Sciences Citation Index (SSCI) for journal articles with proxy efficacy and proxy in their titles, and found only a few articles, mostly related to health and physical exercise (e.g., Bray \& Cowan, 2002; Bray, Gyurcsik, Culos-Reed, Dawson, \& Martin, 2001; Priebe, Flora, Ferguson, \& Anderson, 2012; Shields \& Brawley, 2006, 2007) and cardiac rehabilitation (e.g., Bray, Brawley, \& Millen, 2006; Bray \& Cowan, 2002). Yau (2013, 2014) studied housing management when residents' associations and property management companies were considered proxies for residents and homeowners; Hanham, Ullman, Orlando, and McCormick (2014) proposed conceptualizing proxy efficacy when technology could be considered a proxy to assist students' learning. Elias and MacDonald (2007) appear to have published the only empirical study involving proxy efficacy in an academic setting. They studied the achievement of a sample of US college students with the students' instructors identified as proxies, and students' high school grade point averages (GPAs) as a predictor variable.

This article contributes to SCT literature in organizational settings (Bandura, 1997; Hannah, Avolio, Luthans, \& Harms, 2008; Wood \& Bandura, 1989). From this perspective, motivational processes may be further understood through the roles of proxies in organizations, and the extent to which proxy efficacy beliefs may be involved in these processes. Although other motivational theories such as expectancy theories in organizational settings (Lawler \& Suttle, 1973) and path-goal theory (Evans, 1996) may assist in the understanding of how proxies may help individuals to attain goals, SCT is specifically utilized here to elaborate proxy efficacy and its role in motivational processes because proxy efficacy is a socio-cognitive and agentic phenomenon, and SCT is the overarching theory in social cognition processes in motivation from an agentic perspective (Bandura, 1997, 2001). Future research can integrate the proxy efficacy construct to some other motivational theories such as goal-setting theory to explain how followers' proxy efficacy for their leader may increase the expectancy of followers that leadership behaviors can predict follower efforts and satisfaction in different situations.

Broadly speaking, a key proposition of this article is that employees, managers, and team members may believe themselves to be more efficacious and motivated when they believe that their organizational proxies are efficacious and act on their behalf to attain their individual goals. In other words, a source of an individual's self-efficacy may be his or her proxy efficacy for an agent who has been chosen or designated as the proxy. From this perspective, employees' self-efficacy for performing their tasks may be related to their proxy efficacy for their leader, especially for those tasks for which they are highly dependent on the leader. Thus, proxy efficacy may contribute to the development of self-efficacy beyond the identified sources of personal agency. This may also be helpful practically for leaders, as leadership capabilities may be identified that are critical for the development of followers' self-efficacy when followers perceive the leader as their proxy for performing different tasks.

Consistent with SCT, formation of proxy efficacy may be explained in much the same terms as sources of other efficacy beliefs (Bandura, 1997). Moreover, development of other efficacy beliefs such as collective efficacy and related organizational behavior may be related, to some extent, to proxy efficacy when proxies (e.g., leaders) are important agents. Particularly in team contexts, we propose that proxy efficacy (e.g., for a team leader), with self-efficacy and 
collective efficacy, may play an important role in motivational processes and team effectiveness, because key team members are likely to be perceived as proxies. We argue this new conceptualization can provide researchers with sharper and more elaborated explanations of the role of efficacy beliefs in team processes.

While proxy efficacy can exist for groups in general, we focus on teams. A team has been defined as a distinguishable set of two or more individuals who interact dynamically, interdependently, and adaptively toward a common and valued goal, who have each been assigned specific roles or functions, and who have a limited life span of membership (Salas, Dickinson, Converse, \& Tannenbaum, 1992). From this perspective, key team members, and the team as a collective, could be proxies for other team members. Being a proxy in teamwork is distinct from only being an active and capable colleague because team members rely on another team member as a proxy in order to attain their individual and team objectives.

A team's leader may be an important proxy agent for the team, because team members may need, and expect, the leader to act on the team's behalf to organize, coordinate, and execute some actions in order to achieve team goals, independently collect organizational resources for the team, or independently coordinate the outcomes of team activities with other teams at different stages of teamwork (Zaccaro et al., 2001). In addition, leaders are generally expected by team members to foster effective interactions and communication among team members and facilitate team processes on behalf of other team members (Zaccaro \& Klimoski, 2002). Team members may also depend on the team leader as their proxy to coordinate team activities or to support an underperforming member to improve his or her performance. Thus, team members may perceive their team leader as their proxy because of both: (1) some formal roles allocated to the team leader by the organization and associated expectations that require team members to rely on their team leader to attain their individual or team goals; and (2) other dependencies on the team leader that may have emerged during teamwork and require team members to rely on their team leader to attain their individual and team goals.

Proxy efficacy may relate to some team leadership roles such as internal leader and external leader (Zaccaro et al., 2009) when team members rely on those members to assist them to reach their individual and team goals. Team members can rely on internal and external leaders who can be considered team members' proxies for leading internal activities and processes (internal leader) and accessing organizational resources and networking (external leader).

Bandura (1997) identified a potential dilemma in the exercise of proxy agency, because it may improve or diminish self-efficacy; indeed, overreliance on proxy agencies may cause people to exercise lower personal agency. Shields and Brawley $(2006,2007)$ found some evidence to support this assertion. However, in some organizational contexts such as teams, when team members perform interdependent and specific individual tasks assigned to each of them (Salas et al., 1992), overreliance on one member that hinders exercising personal agency by other team members may be rare. Thus, it may be argued that proxy efficacy in team contexts generally plays a positive role when team members act interdependently to attain individual and team objectives.

In this article, first, the contribution of the proxy efficacy construct in the team leadership literature is discussed. Second, the nature of proxy efficacy is explored, comparing the construct to similar constructs and explaining how proxy efficacy is developed. Then, some specific implications of the construct for team leadership contexts are discussed. Finally, some directions for future empirical research are proposed.

\section{Contribution of the Proxy Efficacy Construct to the Team Leadership Literature}

It can be argued that the extent to which team members perceive their team leader to be capable of performing team leadership functions as their proxy can influence the extent to which the team leader's behaviors and activities contribute to team effectiveness. Zaccaro and colleagues (2001) suggested, "a critical task for researchers in team leadership, then, becomes the definition and validation of the contextual influences that enhance the efficacy of some leadership actions and diminishes others" (p. 455). This literature consists of discussions of both leader-centric and team-centric leadership (Zaccaro et al., 2009). The leader-centric approach is used in the following sections when conceptualizing proxy efficacy for team leader, and the team-centric approach when discussing shared leadership in teams.

We suggest that proxy efficacy for team leader as an individual belief can influence team processes by influencing team members' self-efficacy for performing their interdependent tasks. As described earlier, team members may depend on their team leader for attaining their individual goals related to their team roles. For example, a team member's self-efficacy for performing his or her task in producing a component of a technical product may be related to his or her proxy efficacy for the team leader in terms of providing financial resources as a result of negotiating with top managers on behalf of the team. In addition, 
at the team level, team proxy efficacy, a shared belief of team members about their team leader's capabilities for performing team leadership functions and activities, can play a role as a contextual factor which influences the extent to which a team leader's activities and behaviors contribute to team success. When team members have high proxy efficacy for their leader, the team leader's salient activities and behaviors are more likely to be perceived as helpful, which may increase team members' expectations of team success. This situation may increase the likelihood of team success through increased effort by team members.

The second theoretical contribution of this article relates to the role of proxy efficacy in the emergence of shared leadership in a team, the team-centric approach (Zaccaro et al., 2009); identifying the antecedents of shared leadership in teams has been acknowledged as a gap in the team leadership literature (Carson, Tesluk, \& Marrone, 2007). We propose that when team members have reasonable levels of proxy efficacy for each other in terms of team leadership functions and/or behaviors, it is likely that shared leadership emerges within a team; possessing proxy efficacy beliefs for each other in terms of team leadership may be an antecedent of team members relying on each other for team leadership, recognized as another antecedent of shared leadership in teams (Carson et al., 2007).

The last contribution of the article to the team leadership literature is our suggestion for advancing the model proposed by Hannah and colleagues (2008). They proposed leadership efficacy as an emergent collective process that develops and shapes dynamically self-efficacy and collective efficacy of a leader, follower, and collective. We propose that the proxy efficacy construct can be added to this model incorporating formation of leadership efficacy, because self-efficacy and collective efficacy in team contexts may be related to team members' proxy efficacy for each other and for the leader.

\section{Proxy Efficacy at the Individual and Team Levels}

\section{Who or What Can be a Proxy?}

A proxy may be an individual, a group, or an organization. In this section, we shall refer to a proxy as a single entity in order to simplify theoretical arguments. An individual may need a proxy for two main reasons (Bandura, 2001). First, although the individual may be capable of performing a task, he may not have sufficient resources or time to perform the task himself, or he may prefer to rely on a proxy because greater productivity may be expected as a consequence (e.g., when a manager delegates a task to a subordinate as her or his proxy). Second, the individual may not have the necessary personal abilities, for example, because of lack of knowledge and skills required for the task, and therefore, must rely on a proxy. Proxy efficacy of an individual for a proxy may, or may not, exist, and if it does, it may range from having no confidence, to having complete confidence, in the proxy to act on the individual's behalf.

\section{Proxy Efficacy as a Task and Context Specific Belief} Consistent with Bandura's $(1986,1997)$ arguments that self-efficacy and collective efficacy are domain and task specific beliefs, it may readily be argued that proxy efficacy also is domain and task specific. Logically, a proxy agent may be perceived as capable of performing certain tasks in a specific domain. However, that proxy agent may not be perceived as capable of acting as a proxy in other tasks and domains. For example, a team leader as a proxy may be considered efficacious for organizing the team's activities, but not for representing the team to upper management. Proxy efficacy is conceptualized as a person's context and task specific belief of a proxy's capability to act on the person's behalf, not a general assessment of another's competencies.

\section{Dimensions of Proxy Efficacy}

Three dimensions of self-efficacy, "level," "generality," and "strength" suggested by Bandura (1997), may also be salient for proxy efficacy. An individual's or team's (proxy) capabilities may be perceived at different levels based on difficulty of task demands. For example, proxy efficacy for simple tasks may generally be greater than for moderate or very difficult tasks. Proxies may be believed to be capable of assisting goal attainment in a specific task, or the belief may be generalized to a range of tasks with similar underlying demands or competencies to the specific task. That is, the generality dimension may apply to proxy efficacy. In addition, proxy efficacy may vary in strength. Individuals or teams as proxies may be evaluated by an individual in terms of the strength of his or her belief in the capability of proxies to assist goal attainment at the various levels identified.

\section{Sources and Some Antecedents of Proxy Efficacy}

It is logical to locate proxy efficacy within SCT (Bandura, 1986, 1997) and with other important elements of the theory such as sources of efficacy beliefs. Sources of proxy efficacy are specific types of antecedents although there are likely to be several other antecedents. Individuals may pay attention to different sources of information that help them develop efficacy beliefs. Bandura (1997) proposed four primary sources of self-efficacy and collective efficacy: mastery experiences, vicarious experiences, verbal persuasion, and physiological and affective states. These sources may provide information about the capabilities of a proxy for performing some tasks in specific domains. 
We argue that the sources of proxy efficacy may be similar to sources of self-efficacy, but with different origins and directions of information. First, people and teams may assess their proxies' capabilities in a given domain based on past successes or failures (mastery) of the proxies in that domain. If people perceive their proxies to be unsuccessful in performing given tasks on their behalf in a specific domain, they may be expected to have low proxy efficacy beliefs. Second, people may vicariously develop efficacy beliefs for their proxies by comparing their proxies' capabilities with the capabilities of similar individuals, or by processing some information from the social environment to compare the proxies with similar individuals. Third, verbal persuasion may also be influential. A person or team's efficacy beliefs for a proxy may be influenced by others' (persuasive) appraisals of the proxy agent's capabilities. Finally, some affective and physical states may be interpreted as evidence of a proxy's capabilities to perform a task. For example, when proxies appear anxious when performing a relevant task, they may be assessed as having low capability for the task. In addition, in the context of completing specific activities, anxiety associated with proxies may be interpreted as the proxies not being capable.

It is argued that one may freely choose a proxy (e.g., a team leader who chooses team members) or be required to work with an entity expected to act as a proxy (e.g., when team leaders are appointed to teams, and team members rely on leaders). From this perspective, in both situations, proxy efficacy may be developed, but the processes are likely to be different. In the first situation, an initial assessment of the capability of an individual who may become a proxy may impact the selection process, and proxy efficacy may develop after the individual is selected as a proxy. For the second situation, because an individual or a team is expected to act as a proxy, proxy efficacy may be developed after receiving information about behaviors or performance of the proxy. This situation is likely in several organizational settings such as team activities when a team leader is designated and/or team members are allocated to the team.

Arguably, after forming a team, team members gradually develop or modify schemas related to each other's domains of knowledge, skills, and expertise (Gibson, 2001; Mohammed \& Dumville, 2001; Wegner, 1987). Some schemas related to proxy efficacy for key team members (who have unique expertise or a special role that strongly impacts team performance), the team as a collective, and self-efficacy for working in the team may be developed or modified by team members. For example, team members may develop proxy efficacy for their leader by paying attention to sources such as the leader's past successes or failures to perform specific tasks on their behalf.

From a different perspective, some other antecedents may also be considered for proxy efficacy. Self-efficacy of the proxy may be an antecedent of proxy efficacy; when proxies perceive themselves to be efficacious, they may put greater efforts into their activities than would otherwise be the case. Thus, there may be information in such situations that engenders beliefs about the efficacy of the proxy. In addition, collective efficacy may also be an antecedent for proxy efficacy when the collective relies on a proxy; when the members of the collective share information about the efficacy of their collective, there may be situations in which their collective efficacy is partly attributed to the efficacy of their proxy in attaining their goals.

\section{Team Proxy Efficacy for Team Leader and its Antecedents}

In addition to proxy efficacy for team leader, we propose that the construct team proxy efficacy for team leader can be used to expand our understanding of team leadership. This refers to a shared belief developed by team members about their team leader's capabilities to act on the team's behalf. It is proposed that collective efficacy and team proxy efficacy for leader can be incorporated into multilevel theoretical frameworks of team leadership.

Consistent with Kozlowski and Klein's (2000) approach to multilevel conceptualization of shared team properties, team proxy efficacy for the leader can be conceptualized from two perspectives: composition and compilation. Kozlowski and Klein argued that composition and compilation approaches must be justified theoretically in the contexts of the theory and based on the nature of phenomena, if they are to be meaningful. From the composition perspective, team members in some situations may possess similar perceptions of their leader's capabilities as a proxy. From the compilation perspective, team proxy efficacy for the leader may emerge as the result of interactions between team members when they exchange information about their team leader's capabilities for performing some team leadership tasks in order to achieve team goals on their behalf. Whether there is a homogeneous or heterogeneous perception of a leader has been an important question in multilevel theories of leadership (Klein \& Kozlowski, 2000). According to Klein and Kozlowski, while some have suggested the homogeneity perspective, there may be different perceptions of a leader given different relationships between a leader and team members in dyadic relationships (Graen \& Uhlbien, 1995).

From the composition perspective, sources of team proxy efficacy for the leader may be similar to sources of proxy efficacy for the leader at the individual level. For example, when a team is formed by members without previous team experiences, the team may develop a shared belief about the leader's proxy capability based on similar information team members receive, and without substantial information exchange. On the other hand, from the compilation 
perspective, different types of information from various sources such as mastery experiences or vicarious experiences may be exchanged between team members in order to develop a shared proxy efficacy belief. For example, after a team failure at the middle mark of a team task, team members may exchange information about their leader's past successes and failures, which may contribute to a shared belief about his capability as a proxy.

Consistent with DeRue, Hollenbeck, Ilgen, and Felts (2010), we argue that the dispersion (within team variability) of proxy efficacy for the leader may consist of four types: shared proxy efficacy for the leader, minority belief, bimodal/multimodal, and fragmented. From this perspective, shared proxy efficacy may facilitate team interaction when it is high due to a positive team atmosphere in which all team members possess similar beliefs about the capabilities of the team leader as their proxy. However, low, shared proxy efficacy for the leader may hinder team effectiveness. Second, minority beliefs (an individual or a subgroup) of proxy efficacy for the leader may also influence a minority's contribution to team processes. When a minority has low proxy efficacy for the leader, it may put little effort into team interactions because of low expectancy of achieving team goals due to perceptions of the low capabilities of the leader as a proxy. In contrast, a minority with high proxy efficacy for the leader may encourage other team members to support the leader and contribute to team processes. Third, a bimodal (or multimodal) configuration may result in subgroups, which could increase conflict and political behaviors, and may in turn decrease team effectiveness. Finally, a fragmentation of team members' proxy beliefs for the team leader may trigger interactions that could lead to the development of a shared belief about the leader. On the other hand, fragmentation could destroy team cohesion if resultant conflict were dysfunctional. These ideas may explain some team dynamics with regard to team members' proxy efficacy for their leader.

\section{Propositions for Future Empirical Investigation}

It has been argued that teams usually have a defined leadership role, even if there are degrees of shared leadership (Zaccaro et al., 2001, 2009). However, some leaders may not be appointed, but emerge over time (e.g., Watson, Johnson, \& Zgourides, 2002; Zaccaro et al., 2001, 2009). If team members are allowed to choose their leader, they likely choose their leader from those members who generally are perceived to be most capable of performing leadership tasks, although there may not necessarily be a consensus about this. Whether leaders are appointed, or emerge, they may be perceived as proxies given the dependency of team members on the team leader in various circumstances.

In this section, some implications of proxy efficacy in the context of team leadership are presented as propositions. Although Zaccaro and colleagues (2001) acknowledged that a team leader's self-efficacy can impact team efficacy and the likelihood of team accomplishment, they did not consider the role of proxy efficacy, which team members may have for their team leader as their proxy. Of course, important provisos are that the leader is perceived as a proxy, and proxy efficacy beliefs exist.

We acknowledge that sources of proxy efficacy may simultaneously and indirectly play a role in the development of self-efficacy. For example, considering the interdependent nature of team tasks, observing a leader's performance in a leadership task could affect an individual team member's self-efficacy for carrying out some team tasks in relation to that leadership task.

When individuals depend on a proxy to achieve their goals, information, which is used to develop proxy efficacy in a specific domain, logically, is likely to be a source of selfefficacy for that domain. When individuals entirely or partly rely on a proxy to achieve a goal on their behalf, their selfefficacy is likely to be related to the extent to which they believe the proxy efficacious for achieving the goal. Similar results have been identified in sport psychology about the relationship between an individual's self-efficacy for effective exercise and proxy efficacy for the coach (e.g., Bray et al., 2001). Indeed, when a person is absolutely dependent on a proxy, self-efficacy and proxy efficacy may essentially be the same phenomenon. We argue that within the teamwork context, the proxy dilemma proposed by Bandura (1997), discussed earlier, is unlikely to occur because each team member is expected to perform a specific task interdependent with other team members (Salas et al., 1992), which enables each member to exercise personal agency to some degrees.

Given the above arguments, and dependency of team members on their team leader for achieving their individual and team goals, it is proposed that team members' selfefficacy for performing tasks may be influenced by the extent to which their team leader as a proxy is perceived to be efficacious, in carrying out tasks to assist the team members to perform those tasks and attain targeted goals.

Proposition 1: A team member's self-efficacy for performing his or her tasks is positively related to his or her proxy efficacy for team leader.

The relationship between self-efficacy and proxy efficacy may be moderated by the extent to which the individual has control over the proxy's behavior with regard to achieving the individual's goals. One may believe strongly 
in a proxy's capabilities to achieve in ways that are relevant to one's success if one has control over the proxy. However, if the individual does not have any control over the proxy and cannot be assured that the proxy will help the individual to succeed, the individual's self-efficacy may be lower than would otherwise be the case. Control may be direct, for example, by bestowing rewards or delegating authority contingent on appropriate behaviors. It may also be indirect by ensuring that the proxy follows some rules that ensure the proxy's actions are consistent with the individual's goals. Control may be via a proxy's internal factors such as her commitment to the individual or to following professional principles. The greater the perceived commitment of the proxy, generally, the greater the contribution proxy efficacy may be expected to make to the relevant selfefficacy.

From this perspective, understanding sources of proxy efficacy and the control that an individual may have over the proxy can explain some of the variance of individuals' self-efficacy across different situations in which individuals depend on a proxy for achieving their goals. This may be a theoretical contribution to the field, as it suggests that an individual's self-efficacy for performing a task likely not only depends on personal sources but also depends on his proxy efficacy belief for key players such as leaders. From this perspective, given the context and task specific nature of proxy efficacy, future studies can be conducted to identify context and task specific leadership capabilities that are critical for the development of followers' selfefficacy for performing their tasks in that specific context. For example, when team members perform a production task in an uncertain environment, their self-efficacy for performing team tasks may be related to their proxy efficacy for their team leader in networking with external authorities for collecting essential resources. However, for idea generation tasks in a cross-functional team, team members' self-efficacy may be related to proxy efficacy for their team leader acting as the third party in conflict management within the team. The above ideas need further theoretical and empirical analysis in future research.

A team member may be influenced by a shared belief about the leader's capabilities developed in the team through mechanisms such as verbal persuasion and vicarious experiences. Some information may be exchanged about the leader's capabilities as a proxy during verbal persuasion or vicarious experiences by every member within the whole team context. Each member may perceive himself or herself to be efficacious in performing his or her tasks if the leader is perceived to be an efficacious proxy by the whole team. That is, the extent to which team members possess a shared belief about their team leader's capabilities in performing his or her tasks (e.g., acquiring resources for the team) may provide information that fosters each member's self-efficacy for performing team tasks, because of the reliance of team members on their team leader as a proxy. As proposed earlier, team proxy efficacy is defined as a shared belief developed by team members about their team leader's capabilities to act on the team's behalf. Thus, it is proposed that a team member's self-efficacy for performing team tasks can also be positively influenced by team proxy efficacy for the team leader.

Proposition 2: A team member's self-efficacy for performing his or her tasks is positively related to the team proxy efficacy for the team leader.

When a team leader possesses strong self-efficacy, he or she likely has had mastery experiences and exhibits effective leadership behaviors. Team members are likely to develop proxy efficacy for the leader through mechanisms such as mastery experiences and verbal persuasion about the capabilities of their team leader as the proxy, and may develop a shared belief at the team level for their leader's capabilities to act on their behalf through information and idea exchanges during team processes. In addition, a team leader's self-efficacy may be formed as a result of some mechanisms such as verbal persuasion within the team. A team leader may pay attention to some information within the team, as a result of team proxy efficacy, that encourages the team leader to perceive himself or herself to be efficacious in those activities upon which other members rely for attaining individual and team goals.

Proposition 3: team proxy efficacy for team leader is positively related to the team leader's self-efficacy for leadership.

The extent to which a team develops collective efficacy may partly impact the team proxy efficacy for team leader if the leader is considered a proxy for achieving team goals; when a team leader is considered a proxy, teams may be expected to relate their success to the achievement of the leader as their proxy.

Proposition 4: Collective efficacy is positively related to team proxy efficacy for team leader.

Although different definitions may be used for team effectiveness (Zaccaro et al., 2001), we define it here to be the extent to which the team achieves team goals. The higher the team proxy efficacy for the leader, the more likely the team will be influenced and motivated by the leader, because of the shared belief that the leader can successfully assist the team to achieve its goals. Team leaders may be relied upon by team members to demonstrate contingent behaviors to lead the team (e.g., participative 
or transformational), but be unsuccessful, because their team members have low levels of proxy efficacy for them. When team members have high proxy efficacy for their leader, they may more likely be influenced by the leader, because of the likelihood of positive outcomes, and consequently, participate in team processes effectively. Similarly, the relationship between a team leader's activities in performing leadership functions suggested by Zaccaro and colleagues (2001) on team effectiveness can be influenced by team proxy efficacy for team leader. They proposed four team leadership processes namely, cognitive, motivational, affective, and coordination. These processes link the role of team leader in team leadership functions to team effectiveness. Team leadership functions have been identified as information search and structuring, information use in problem solving, managing personnel resources, and managing material resources (Fleishman et al., 1992; Zaccaro et al., 2001).

The role of team proxy efficacy for team leadership proposed above is theoretically important as Zaccaro and colleagues (2001) suggested, "a critical task for researchers in team leadership, then, becomes the definition and validation of the contextual influences that enhance the efficacy of some leadership actions and diminishes others" (p. 455). For motivational functions, Zaccaro and colleagues emphasized collective efficacy and team task cohesion as two key motivational factors at the team level. The former motivates team members to become involved in team activities because of the increased possibility of success when the team is perceived to be capable of achieving its goal (Bandura, 1997), and the latter helps team members to become focused and integrated when working interdependently, especially when a team faces challenges or failures. We propose that team proxy efficacy for team leader may also be considered a motivational factor for team members in participating in teamwork, and can augment the role of team leader in team success for achieving its goals. The following Proposition is posited.

Proposition 5: Team proxy efficacy moderates the relationship between team leader's role in team leadership behaviors and functions with team effectiveness in a way that when team proxy efficacy is high, the relationship is stronger than when team proxy efficacy is low.

It can be argued that proxy efficacy can contribute to the leadership efficacy process proposed by Hannah et al. (2008). They proposed that an emergent collective process may exist within the context of interactions between a leader, followers, and collective that dynamically develops and shapes efficacy beliefs in relation to self and collective. Hannah and colleagues reviewed the leadership efficacy literature and proposed directions for further research. They defined leaders' (followers') efficacy as 'beliefs in their perceived capabilities to organize the positive psychological capabilities, motivation, means, collective resources, and courses of action required to attain effective, sustainable performance across their various leadership roles, demands, and contexts" (p. 670). They proposed that leader efficacy, follower efficacy, and collective efficacy have triadic reciprocal influences, which may develop an emergent collective process namely leadership efficacy. According to this model, a leader has dyadic relationships with his or her individual followers, and during their interactions, they develop beliefs about their own capabilities (leader efficacy and follower efficacy), and from group behaviors and interactions, they will gradually develop collective efficacy, which in turn, will influence their collective performance.

We argue that proxy efficacy can expand this model by incorporating proxy efficacy for the leader held by followers (team members), proxy efficacy for the whole team held by the leader, proxy efficacy for key team members held by the leader and other team members, and team proxy efficacy for the team leader shared by team members. From this perspective, during dyadic interactions between a team leader and followers, proxy efficacy beliefs at multiple levels may be developed, and team members may also develop team proxy efficacy for their leader during team interactions and behaviors. Moreover, leaders may be expected to develop and modify their relevant selfefficacy beliefs. However, we emphasize that team members may hold quite discordant views about the leader's capability to act on the team's behalf, precluding the existence of a collective cognitive phenomenon. We argue that the extent to which followers are likely to be influenced by their leader may partly be related to their proxy efficacy for their leader. Incorporating the proxy efficacy construct into the model proposed by Hannah and colleagues (2008) can enhance the explanatory nature of the model by explaining that the self-efficacy of leaders and their followers, and collective efficacy, may be influenced by proxy efficacy beliefs that the leader and followers hold for each other.

Several propositions may be developed for the contribution of proxy efficacy at different levels in the leadership efficacy process, only one relationship is specifically proposed here. Leadership efficacy as the outcome of an emerging leadership process may be fostered when team members possess strong proxy efficacy for team leader, because team leader as a proxy for leading the team likely is an important agency for the success of the whole team and team leadership. A proposition is provided here in relation to the role of team proxy efficacy for team leader. 
Proposition 6: Leadership efficacy is positively related to team proxy efficacy for team leader.

It is suggested that in some organizational settings, such as those with team structures, in addition to the traditional view of vertical leadership (one person has the main leadership responsibilities), shared leadership may be practiced (Carson et al., 2007; Zaccaro et al., 2009). Because vertical leadership may differentially be important in team processes in different types of teams for achieving high performance (Zaccaro et al., 2009), we argue that team proxy efficacy for team leader may be more salient when the quality of vertical leadership is more important for team effectiveness than shared leadership, because, the role of vertical leaders in team success may be perceived to be more critical than other roles.

Leadership may be distributed, rotated, or even dynamically emerge among team members (Zaccaro et al., 2009). There seems to be a gap in the literature explaining how shared leadership may emerge in a team (Carson et al., 2007). It has been suggested that for emergent shared leadership, two factors must exist: first, team members offer their contribution to team leadership, and second, team members rely on each other in leading the team (Katz \& Kahn, 1978). Although self-efficacy for contributing to shared leadership seems to be critical, we propose that team members' proxy efficacy for each other may also play important roles in forming shared leadership in team contexts, because proxy efficacy may impact the extent to which team members rely on each other in leading the team. The extent to which team members possess proxy efficacy for each other for playing shared or distributed parts of team leadership may make team members confident that the whole team is capable of leading itself toward full execution of team leadership; team members' proxy efficacy for each other may increase the extent to which they rely on each other during team leadership. This suggests a likely relationship between shared leadership and team members' proxy efficacy for each other for functions of team leadership. However, it can be argued that this relationship may be influenced by the structural nature of shared leadership (Mehra, Smith, Dixon, \& Robertson, 2006). When team leadership is distributed among members in a non-fragmented structure, the above relationship may exist. While in a shared structure every member is reasonably involved in shared leadership, in a fragmented structure, some may be involved in functions of team leadership without coordination with other team members (Mehra et al., 2006). Therefore, we posit the following Proposition.

Proposition 7: Shared leadership is positively related to the mean of team members' proxy efficacy for each other for distributed components of team leadership functions, when team leadership is nonfragmented.

\section{Conclusion}

It has been argued that self-efficacy, proxy efficacy, and collective efficacy are interrelated in team contexts. In some situations, a personal agent depends on a proxy agent to achieve personal goals. The proxy efficacy construct can help researchers to broaden their understanding of efficacy beliefs in motivational processes of team leadership.

In several situations, relationships between individuals in organizational settings can be explained using the proxy agent concept. This is beneficial, because SCT can be used to explain why we rely on others to perform some tasks on our behalf in organizational settings. An employee's selfefficacy for performing his or her tasks may to some extent be related to his or her proxy efficacy beliefs for other colleagues when they depend on each other to achieve individual and team goals. Although the extent to which an individual perceives he has control over the performance of the proxy may moderate the relationship between selfefficacy and proxy efficacy. This adds to our understanding of how self-efficacy can be developed in organizational settings. This article proposes that efficacy sources (e.g., mastery and vicarious experiences) suggested by Bandura can also be used to explain how proxy efficacy is developed. However, the origins and directions of information may be different. We argue this theoretical perspective is novel in explaining how an individual may be perceived capable as a proxy when he or she is perceived as a proxy.

Proxy efficacy for team leader may be important when team members develop collective efficacy for their team. Especially, when the team leader is expected to act as their proxy for performing key roles for which team members rely on the leader. In addition, it was suggested that collective efficacy may be associated with team proxy efficacy for the leader, as a team level antecedent. These propositions may contribute to our understanding of the development process of collective efficacy in team contexts. We have proposed that the contribution of team leadership activities and behaviors to team effectiveness may greatly depend on team members' proxy efficacy for their team leader.

Past studies of shared leadership suggested future research should focus on how shared leadership emerges in teams. Team members' proxy efficacy for each other for participating in team leadership processes may influence team members' self-efficacy for leadership as well 
as reliance on each other in leading their team. This article suggests that team members' proxy efficacy for each other for functions of team leadership may result in increased levels of shared leadership.

We propose conducting empirical investigations of proxy efficacy generally, and of the posited propositions specifically in team leadership and other organizational contexts.

\section{References}

Baker, D. F. (2001). The development of collective efficacy in small task groups. Small Group Research, 32, 451-474.

Bandura, A. (1986). Social foundations of thought and action. Upper Saddle River, NJ: Prentice-Hall.

Bandura, A. (1993). Perceived self-efficacy in cognitive development and functioning. Educational Psychologist, 28, 117-148.

Bandura, A. (1997). Self-efficacy: The exercise of control. New York, NY: Freeman and Company.

Bandura, A. (2000). Exercise of human agency through collective efficacy. Current Directions in Psychological Science, 9, 75-78.

Bandura, A. (2001). SCT: An agentic perspective. Annual Review of Psychology, 52, 1-26.

Bray, S. R., Brawley, L. R., \& Millen, J. A. (2006). Relationship of proxy efficacy and reliance to home-based physical activity after cardiac rehabilitation. Rehabilitation Psychology, 51, 224-264.

Bray, S. R., \& Cowan, H. (2002). Personal and proxy efficacy beliefs as predictors of exercise enjoyment and adherence in cardiac rehabilitation. Journal of Sport and Exercise Psychology, 24, 37-38.

Bray, S. R., Gyurcsik, N. C., Culos-Reed, S. N., Dawson, K. A., \& Martin, K. A. (2001). An exploratory investigation of the relationship between proxy efficacy, self-efficacy and exercise attendance. Journal of Health Psychology, 6, 425-434.

Carson, J. B., Tesluk, P. E., \& Marrone, J. A. (2007). Shared leadership in teams: An investigation of antecedent conditions and performance. Academy of Management Journal, 50, 1217-1234.

Collins, C. G., \& Parker, S. K. (2002). Predicting team effectiveness: Importance of collective outcome efficacy and collective process efficacy. Paper presented at the Academy of Management Meeting, Sydney.

DeRue, D. S., Hollenbeck, J., Ilgen, D., \& Felts, D. (2010). Efficacy dispersion in teams: Moving beyond agreement and aggregation. Personnel Psychology, 63, 1-40.

Druskat, V. U., \& Wheeler, J. V. (2004). How to lead a selfmanaging team. MIT Sloan Management Review, 45, 64-71.

Elias, S., \& MacDonald, S. (2007). Using past performance, proxy efficacy, and academic self-efficacy to predict college performance. Journal of Applied Social Psychology, 37, 2518-2531.

Evans, M. G. (1996). R. J. House's "A path-goal theory of leader effectiveness". The Leadership Quarterly, 7, 305-309.

Fleishman, E. A., Mumford, M. D., Zaccaro, S. J., Levin, K. Y., Korotkin, A. L., \& Hein, M. B. (1992). Taxonomic efforts in the description of leader behavior: A synthesis and functional interpretation. The Leadership Quarterly, 2, 245-287.

Gibson, C. B. (2001). From knowledge accumulation to accommodation: Cycles of collective cognition in work groups. Journal of Organizational Behavior, 22, 121-134.
Graen, G. B., \& Uhlbien, M. (1995). Relationship-based approach to leadership - Development of Leader-Member Exchange $(L M X)$ Theory of leadership over 25 Years - Applying a multilevel multidomain perspective. Leadership Quarterly, 6, 219-247.

Hanham, J., Ullman, J., Orlando, J., \& McCormick, J. (2014). Intentional learning with technological proxies: Goal orientations and efficacy beliefs. Australian Journal of Education, 58, 36-49.

Hannah, S. T., Avolio, B. J., Luthans, F., \& Harms, P. D. (2008). Leadership efficacy: Review and future directions. Leadership Quarterly, 19, 669-692.

Katz, D., \& Kahn, R. L. (1978). The social psychology of organizations (2nd ed.). New York, NY: Wiley.

Kellett, J. B., Humphrey, R. H., \& Sleeth, R. G. (2000, November). We're great vs. you're lazy: How goal difficulty influences social loafing, collective efficacy and perceived team ability. Paper presented at the annual meeting of the Southern Management Association, Orlando, FL.

Klein, K. J., \& Kozlowski, S. W. J. (2000). From micro to meso: Critical steps in conceptualizing and conducting multilevel research. Organizational Research Methods, 3, 211-236.

Kozlowski, S. W., \& Klein, K. J. (2000). A multilevel approach to theory and research in organizations: Contextual, temporal, and emergent processes. In K. J. Klein \& S. W. J. Kozlowski (Eds.), Multilevel theory, research, and methods in organizations (pp. 349-381). San Francisco, CA: Jossey-Bass.

Lawler, E. E., \& Suttle, J. L. (1973). Expectancy theory and job behavior. Organizational Behavior and Human Performance, 9, 482-503.

Mehra, A., Smith, B. R., Dixon, A. L., \& Robertson, B. (2006). Distributed leadership in teams: The network of leadership perceptions and team performance. The Leadership Quarterly, 17, 232-245.

Mohammed, S., \& Dumville, B. (2001). Team mental models in team knowledge framework: Expanding theory and measurement across disciplinary boundaries. Journal of Organizational Behavior, 22, 89-106.

Pajares, F. (1996). Self-efficacy beliefs in academic settings. Review of Educational Research, 66, 543-578.

Priebe, C. S., Flora, P. K., Ferguson, L. J., \& Anderson, T. J. (2012). Using efficacy information to manipulate proxy efficacy in novice exercisers. Psychology of Sport and Exercise, 13, 562-568.

Salas, E., Dickinson, T. L., Converse, S., \& Tannenbaum, S. I. (1992). Toward an understanding of team performance and training. In R. W. Swezey \& E. Salas (Eds.), Teams: Their training and performance (pp. 3-29). Norwood, NJ: Ablex Publishing.

Shields, C. A., \& Brawley, L. R. (2006). Preferring proxy-agency impact on self-efficacy for exercise. Journal of Health Psychology, 11, 904-914.

Shields, C. A., \& Brawley, L. R. (2007). Limiting exercise options depending on a proxy may inhibit exercise self-management. Journal of Health Psychology, 12, 663-671.

Watson, C. B., Chemers, M. M., \& Preiser, N. (2001). Collective efficacy: A multi-level analysis. Personality and Social Psychology Bulletin, 27, 1057-1068.

Watson, W. E., Johnson, L., \& Zgourides, G. D. (2002). The influence of ethnic diversity on leadership, group process, and performance: an examination of learning teams. International Journal of Intercultural Relations, 26, 1-16.

Wegner, D. M. (1987). Transactive memory: A contemporary analysis of the group mind. In B. Mullen \& G. R. Goethals (Eds.), Theories of group behavior. New York, NY: Springer.

Wood, R. E., \& Bandura, A. (1989). SCT of organizational management. Academy of Management Review, 14, 361-384. 
Yau, Y. (2013). Willingness to participate in collective action: The case of multiowned housing management. Journal of Urban Affairs, 35, 153-171.

Yau, Y. (2014). Perceived efficacies and collectivism in multiowned housing management. Habitat International, 43, 133-141.

Zaccaro, S., Heinen, B., \& Shuffler, M. (2009). Team leadership and team effectiveness. In E. Salas, G. Goodwin, \& C. Burke (Eds.), Team effectiveness in complex organizations (pp. 113-156). New York, NY: Psychology Press.

Zaccaro, S. J., \& Klimoski, R. (2002). The interface of leadership and team processes. Group \& Organization Management, 27, 4-13.

Zaccaro, S. J., Rittman, A. L., \& Marks, M. A. (2001). Team leadership. The Leadership Quarterly, 12, 451-483.

Received August 25, 2015

Revision received March 29, 2016

Accepted June 21, 2016

Published online September 8, 2016

\section{Seyyed Babak Alavi}

Graduate School of Management and Economics

Sharif University of Technology

Teimoori Blvd

Habibollahi Ave., Azadi st.

Tehran

Iran

Tel. +9821660 22755-7

Fax +9821660 22759

E-mailsbalavi@sharif.edu

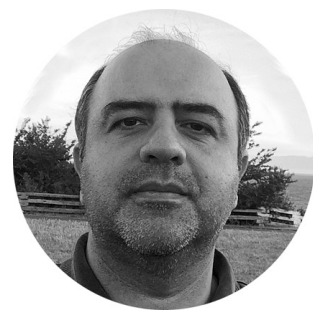

Seyyed Babak Alavi is an Associate Professor at the Graduate School of Management and Economics at Sharif University of Technology, Tehran, Iran. His research interests, teaching, and consultancy relate to organizational behavior and leadership and human resource development. More specifically, he is currently involved in research on authenticity and self-determination theory in organizational contexts, feedback seeking behaviors, authentic leadership, team leadership, efficacy beliefs, and change processes.

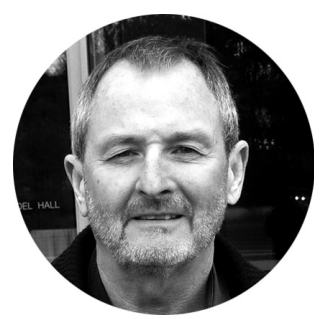

John McCormick is an Honorary Professional fellow of the University of Wollongong, Australia, and an independent educational consultant. His research interests, publications, and consultancy relate to various aspects of motivation, including self-efficacy, leadership, teamwork, group cognitive processes, occupational stress, organizational decision-making, and cross-cultural differences in organizational behavior. 